\title{
PENERAPAN KURIKULUM MUHAMMADIYAH PADA SD MUHAMMADIYAH KOTA PADANG
}

\author{
Armalena $^{1}$, Syahrizal ${ }^{2}$ \\ Universitas Muhammadiyah Sumatera Barat ${ }^{1}$, Universitas PGRI Sumatera Barat ${ }^{2}$ \\ lena49075@gmail.com
}

\begin{abstract}
The Muhammadiyah organization in the city of Padang has not maximally supervised the existing curriculum in Muhammadiyah schools, especially $S D$ Muhammadiyah as a hallmark of Muhammadiyah schools. This is a serious challenge for administrators and policy makers in this organization because of the influence of school principals who are too dependent on the government curriculum without giving room to implement the existing curriculum in Muhammadiyah schools. This study aims to analyze and ensure the implementation of the existing Muhammadiyah curriculum in Muhammadiyah schools. This survey was conducted to collect data on 100 students and 30 teachers as well as 10 principals of SD Muhammadiyah which were randomly selected using observation, interview and documentation data collection techniques. This study found that the implementation of the Muhammadiyah curriculum in Muhammadiyah elementary schools did not run properly in accordance with the mandate of the curriculum. As a result, Muhammadiyah elementary school students do not know about the characteristics of the Muhammadiyah school curriculum. The results show that the policies of the management of the Muhammadiyah organization in the city of Padang and the supervision of the principal as an agent of professional change and guidance to teachers will be able to change the mainset that the implementation of the curriculum in Muhammadiyah schools is important because it is a characteristic that must be preserved.
\end{abstract}

\section{Keywords: Curriculum, Muhammadiyah School, Student, Teacher, Headmaster}

\begin{abstract}
Abstrak: Organinisasi Muhammadiyah Kota Padang belum maksimal mengawal kurikulum yang ada pada sekolah-sekolah-sekolah Muhammadiyah terutama SD Muhammadiyah sebagai pencri khas dari sekolah-sekolah Muhammadiyah. Ini menjadi sebuah tantangan berat bagi pengurus dan pengambil kebijakan pada organisasi ini karena pengaruh kepala sekolah yang terlalu berpatokan kepada kurikulum pemerintah tanpa memberikan ruang untuk melaksanakan kurikulum yang ada pada sekolah Muhammadiyah. Penelitian ini bertujuan untuk menganalisis dan memastikan penerapan kurikulum Muhammadiyah yang ada pada sekolah-sekolah Muhammadiyah. Survei yang dilakukan ini mengumpulkan data 100 siswa dan 30 guru serta 10 kepala sekolah SD Muhammadiyah yang dipilih secara acak dengan menggunakan teknik pengumpulana data pengamatan, wawancara dan dokumentasi. Penelitian ini menemukan bahwa penerapan kurikulum Muhammadiyah pada sekolah dasar Muhammadiyah tidak berjalan dengan semestinya sesuai dengan amanah kurikulum tersebut. Akibatnya siswa-siswa SD Muhammadiyah tidak mengetahui adanya ciri khas dari kurikulum sekolah Muhammadiyah. Hasilnya menunjukkan bahwa kebijakan dari pengurus organisasi Muhamamdiyah kota Padang dan adanya pengawasan kepada kepala sekolah sebagai agen perubahan professional serta pembinaan kepada guru-guru akan dapat mengubah mainset bahwa penerapan kurikulum pada sekolah-sekolah Muhammadiyah penting diterapkan karena merupakan ciri khas yang harus dilestarikan.
\end{abstract}

Kata kunci: Kurikulum, Sekolah Muhammadiyah, Siswa, Guru, Kepala Sekolah 


\section{PENDAHULUAN}

Penduduk kota Padang saat ini lebih kurang 962.000 jiwa. $^{i}$ Organisasi massa yang hidup dan berkembang di tengah masyarakat kota Padang umumnya adalah Muhammadiyah. Organisasi Muhammadiyah telah banyak berbuat untuk kemajuan bangsa dan negara serta agama. Melalui berbagai amal usahanya, seperti rumah sakit, klinik, panti asuhan, dan pendidikan khususnya pendidikan tinggi telah mengalami perkembangan dan kemajuan.

Namun, disisi lain seperti program kaderisasi belum menunjukkan kemajuan yang membanggakan khususnya kaderisasi secara terencana mulai dari tingkat yang paling bawah yaitu tingkat pendidikan Sekolah Dasar. Program kaderisasi biasanya dilakukan oleh organisasi otonom di bawah naungan Muhammadiyah mulai dari pimpinan pusat, wilayah, daerah, cabang dan ranting. Menurut penulis, belum ada program kaderisasi berjenjang mulai dari usia dasar atau sekolah dasar. Jika keadaan ini terus berlangsung dikuatirkan habisnya pelanjut yang akan menjaga eksistensi Muhammadiyah baik dari aspek organisasi maupun pemahaman keagamaannya.

Selanjutnya, penulis berasumsi bahwa tidak adanya program kaderisasi ini apakah ada hubungannya dengan penerapan kurikulum Muhammadiyah pada sekolah-sekolahnya yang tidak berjalan dengan baik. Penulis sebagai salah seorang kader pun ketika bersekolah di SD Muhammadiyah 7 Air Mati kecamatan Padang Timur kota Padang antara tahun 1987-1993 tidak mendapati pelaksanaan kurikulum yang mencari ciri khas sekolah Muhammadiyah.

Sesuai dengan tujuan pendirian Muhammadiyah yang digagas oleh KH. Ahmad Dahlan pada tahun 1912 M bahwa akan menciptakan kepribadian intelek dan ulama dari sistim pendidikan yang mengintegrasikan pelajaran umum dan pelajaran agama. Maka sudah tepat kurikulum yang dicetuskan oleh beliau untuk membentengi diri generasi Islam dari gempuran sekulerisme. Hal ini pun telah sesuai 
dengan Undang-undang R.I. No 20 tahun 2003 tentang Sistem Pendidikan Nasional.ii

Seiring perkembangan trend pada kurikulum, maka integrasi kurikulum umum dan kurikulum agama mulai pudar bahkan cenderung hilang pada sekolah-sekoalah Muhammadiyah. Kurikulum yang cenderung tidak lagi diterapkan seperti mata pelajaran pendidikan agama hanya satu mata pelajaran saja. Seharusnya mata pelajaran agama itu dibagi ke dalam mata pelajaran turunannya yaitu: Akidah, al-Qur'an, tarikh dan akhlak. Al-Qur'an memerintahkan agar menjaga eksistensi sebuah generasi. QS.4:9

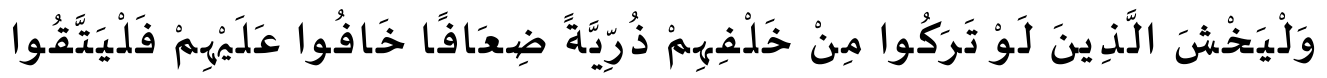

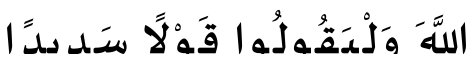

Artinya: "Dan hendaklah takut kepada Allah orang-orang yang seandainya meninggalkan dibelakang mereka anak-anak yang lemah, yang mereka khawatir terhadap (kesejahteraan) mereka. Oleh sebab itu hendaklah mereka bertakwa kepada Allah dan hendaklah mereka mengucapkan perkataan yang benar"iii

Di samping itu, Nabi Muhammad SAW mengingatkan khususnya kepada orang tua dan umumnya kepada generasi tua agar selalu menjaga dan mengarahkan generasi muda ke arah yang lebih baik.

$$
\text { عن على أبي هريرة رضي الله عنه قال : قال النبي صلى الله عليه وسلم كل مولود يولد }
$$

Artinya: "Dari Abu Hurairah ra berkata: Bersabda Nabi SAW: Setiap bayi yang dilahirkan dalam keadaan suci maka orang tuanyalah yang mempengaruhinya menjadi Yahudi, Nasrani atau Majusi sebagaimana ia tumbuh dan berkembang sampai jadi kakek-kakek". (HR. Bukhari). iv

Kata kunci dari ayat dan hadis di atas dapat dipahami adalah kepedulian generasi saat ini kepada generasi muda menjadi titik sentral. Strateginya adalah dengan adanya rancangan atau peta jalan yang dapat 
diukur ketercapaiannya dalam membina dan membimbing generasi muda saat ini.

Selanjutnya, tujuan penelitian ini adalah bagaimana organisasi Muhammadiyah dalam amal usahanya dibidang pendidikan agar dapat mengontrol terlaksananya penerapan kurikulum pendidikan yang menjadi khas dari sekolah-sekolah Muhammadiyah. Hal ini sangat penting dilakukan karena dengan adanya penerapan kurikulum khas yang ada dapat dipastikan terjaganya eksistensi generasi pelanjut dari organisasi Muhammadiyah di masa mendatang.

\section{METODE}

Metode penelitian yang dipergunakan dalam penelitian ini adalah metode kualitatif. Pendekatan penelitian kualitatif disebut juga sebagai metode penelitian naturalistik dikarenakan penelitian yang dilakukan ini dalam kondisi alamiah (natural setting). Unsur dalam penelitian kualitatif ini memerlukan kecermatan dan langkah sistematis pun memegang peranan sangat urgen.

Penggunakan pendekatan kualitatif ini menuntut peneliti lebih leluasa dalam memahami, mengamati dan menganalisis serta melakukan penelaahan lebih akurat berkenaan penerapan kurikulum Muhammadiyah pada sekolah-sekolah Muhammadiyah terutama pada SD Muhammadiyah. Oleh karenanya, metode penelitian kualitatif dapat diharapkan mampu mendeskripsikan dan menjelaskan tentang penerapan kurikulum Muhammadiyah pada sekolah-sekolah Muhammadiyah yang menjadi ciri khas sejak didirikannya organisasi Muhammadiyah.

\section{HASIL}

Kurikulum yang dipakai oleh sekolah-sekolah Muhammadiyah adalah kurikulum yang mengintegrasikan kurikulum umum dan agama. Seperti bidang studi Pendidikan agama Islam tidak hanya satu mata pelajaran 
saja, akan tetapi dipecah dan diturunkan menjadi mata pelajaran Akidah, al-Qur'an, tarikh dan akhlak. Keempat mata pelajaran ini menjadi faktor penting dalam meningkatkan pengetahuan yang lebih detail dalam mempelajari materi-materi dalam memahami ajaran Islam. Hasil penelitian menemukan hal yang patut dibenahi dari segala aspek yang ada yaitu secara umum penerapan kurikulum Muhammadiyah pada sekolah-sekolah Muhammadiyah terutama pada tingkat SD Muhammadiyah yang menjadi fokus penelitian ini tidak terlaksana.

Seratus orang siswa kelas IV dan V dari sepuluh sekolah Muhammadiyah Kota Padang yang menjadi objek penelitian telah diwawancarai secara acak ketika ditanyakan apakah ada belajar mata pelajaran akidah, al-Qur'an, tarikh dan akhlak secara khusus?. Maka secara umum para siswa tersebut menjawab bahwa selama bersekolah belum pernah ada belajar mata pelajaran yang ditanyakan. ${ }^{v}$

Selanjutnya, tiga puluh orang guru SD Muhammadiyah dipilih secara acak ketika ditanyakan kepada mereka apakah mengetahui bahwa ada kurikulum khas yang menjadikan SD Muhammadiyah berbeda dengan SD lainnya apalagi dengan SD Negeri? Jawaban secara umum oleh guru adalah mengetahui adanya kurikulum khas tersebut namun dalam pelaksanaannya tidak terwujud.

Kemudian, 10 orang kepala sekolah SD Muhammadiah Kota Padang yang pada umumnya adalah seorang pegawai negeri sipil (PNS), ketika ditanyakan kenapa penerapan kurikulum yang menjadi Amanah organisasi Muhammadiyah tidak terlaksana.? Secara umum jawabannya adalah karena alokasi waktu tidak memungkinkan untuk menambah jam pembelajaran pada mata pelajaran yang telah disebutkan. 


\section{PEMBAHASAN}

Hasil penelitian di atas menunjukkan kontrol dan kualitas kontrol dari pemangku kebijakan organisasi Muhammadiyah Kota Padang masih lemah. Pada struktur organisasi Muhammadiyah ada bagian khusus yang membawahi pelaksanaan amal usaha bidang pendidikan Muhammadiyah yang sering disebut dengan Majlis Pendidikan Dasar dan Menengah (Dikdasmen). Majlis Pendidikan dasar dan menengah inilah yang memiliki wewenang untuk mengontrol dan mengawasi terlaksananya kurikulum yang ada pada sekolah-sekolah Muhammadiyah.

Visi Disdakmen PP Muhammadiyah adalah: "Berkembangnya fungsi pendidikan dasar dan menengah Muhammadiyah mencakup sekolah, madrasah, pondok pesantren yang berbasis Al Islamkemuhammadiyahan, holistik intergratif, bertata kelola baik, serta berdaya saing dan berkeunggulan.” Sementara salah satu dari misinya adalah: “ Menyelenggarakan pendidikan dasar dan menengah yang holistik dan integratif yakni mengembangkan potensi akal, hati, dan keterampilan yang seimbang dan Menyelenggarakan pendidikan dasar dan menengah yang didukung iptek dan imtaq."vi

Visi dan misi ini mengamanahkan kepada seluruh pengurus organisasi Muhammadiyah agar melaksanakan bidang pendidikan sesuai dengan semestinya. Tentunya, amanah ini akan terlaksana apabila kurikulum yang telah digariskan oleh organisasi Muhammadiyah penerapannya terlaksana di sekolah-sekolah Muhammadiyah.

Penelitian yang dilakukan oleh Joko Susilo dengan judul Strategi Membangun Sekolah Muhammadiyah yang Berkemandirian. Lokasi penelitiannya berada di daerah Malang. Hasil dari penelitian ini menjelaskan bahwa strategi terlaksananya sekolah yang berkemajuan itu, salah satu item di dalamnya pasti terlaksananya penerapan kurikulum sekolah Muhammadiyah yaitu 1, Mengubah arah kebijakan berkemajuan, 2. Membangun leadership yang Tangguh, 3. Menciptakan budaya yang berkesejahteraan, 4.Mempererat jejaring sekolah. vii 
Lebih lanjut, dalam Pedoman Pimpinan Pusat Muhammadiyah Nomor 01/Ped/I.0/B/2018 Tentang Pendidikan Dasar dan Menengah Muhammadiyah dijelaskan pada pasal 37 ayat satu tentang kurikulum bahwa Kurikulum pada SD/SDLB/SMP/SMPLB atau bentuk lain yang sederajat dan SMA/SMALB/SMK atau bentuk lain yang sederajat merupakan satu kesatuan integral dari kurikulum Pemerintah dan Persyarikatan. viii

Penjelasan di atas, mestinya sudah cukup dipahami oleh seluruh pihak yang terlibat dalam penyelenggaraan pendidikan Muhammadiyah terutama pada sekolah SD Muhammadiyah agar penerapan kurikulum tersebut dalam dilakukan dengan baik dan di bawah kontrol dari pihak yang telah diamanahkan oleh organisasi Muhammadiyah.

\section{KESIMPULAN}

Hasil penelitian ini dapat disimpulkan bahwa penerapan kurikulum sekolah-sekolah SD Muhammadiyah di Kota Padang belum terlaksana sebagaimana mestinya sesuai dengan amanah oleh organisasi Muhammadiyah. Di samping belum berjalannya sebagai mestinya juga pengawasan atau kontrol dari bagian dari Majlis Pendidikan Dasar dan Menengah (Disdakmen) belum berjalan. Oleh karena itu, disarankan agar temuan ini supaya ditindaklanjuti oleh pihak-pihak yang bertanggungjawab dan berkompetensi dalam menjalankan amanah ini.

\section{UCAPAN TERIMA KASIH}

Penelitian ini berhasil berkat lembaga dan individu serta ucapan terima kasih yang setinggi-tingginya sebagai berikut:

1. Pimpinan Wilayah Muhammadiyah Sumatera Barat

2. Rektor Universitas Muhammadiyah Sumatera Barat

3. Pimpinan Daerah Muhammadiyah Kota Padang

4. Pihak-pihak yang tidak disebutkan satu persatu yang ikut berkontribusi 


\section{DAFTAR PUSTAKA}

[1] Depertemen Agama RI,. (1995). Al-Qur'an dan Terjemahnya, Semarang: Toha Putra Semarang.

[2] Depdikbud. (1997). Pedoman Administrasi Sekolah Dasar, Jakarta: Balai Pustaka.

[3] ------------. (1994). Administrasi Kurikulum Pendidikan Dasar, Jakarta: Depdikbud.

[4] -------------. (2003). Sistem Pendidikan Nasional, Jakarta: Depdiknas.

[5] Gunawan, H. Ary. (2011). Administrasi Sekolah, Jakarta: Rineka Cipta.

[6] Hadi, Sutrisno. (2004). Metodologi Research Jilid III, Jogyakarta: Fakultas Psikologi UGM.

[7] Hadiyanto. (2000). Manajemen Peserta Didik, Padang: UNP Press.

[8] Hamalik, Oemar. (1993). Psikologi Manajemen, Bandung: Trigenta Karya.

[9] Harjanto. (2003). Perencanaan Pengajaran, Bandung: Rineka Cipta.

[10] Hasibuan, S.P. Malayu. (2009). Manajemen Sumber Daya Manusia, Jakarta: Bumi Aksara.

[11] Ibrahim, Bafadal. (2004). Dasar-dasar Manajemen dan Supervisi, Jakarta: Bumi Aksara.

[12] Johar, Mulyani, dkk. (1999). Strategi Belajar Mengajar, Jakarta: Depdikbud.

[13] J. Moeloeng Lexy. (2000). Metodologi Penelitian Kualitatif, Bandung: Remaja Rosdakarya.

[14] Lazaruth, Soewadji. (1994). Kepala Sekolah dan Tanggungjawabnya, Yogyakarta: Kanisius.

[15] Mulyasa. (2003). Manajemen Berbasis Sekolah, Bandung: Remaja Rosdakarya. 
[16] Hasbiyallah dan . Sulhan, Muhammad. (2013). Hadis Tarbawi dan HadisHadis di Sekolah dan Madrasah, Bandung.c Citing internet sources URL http://digilib.uinsgd.ac.id/10984/1/hadits\%20tarbawi.pdf

[17] Badan Pusat Statistik Nasioanal Kota Padang. (2020). Citing internet sources URL https://www.dilut.com/jumlah-penduduk-kota-padang (diakses pada tanggal 01 Maret 2021)

[18] Visi dan Misi Disdakmen. (2021). Citing internet sources URL https://dikdasmenppmuhammadiyah.org/visi-misi/

[19] Joko Susilo. (2020). Seminar Nasional Kedua Pendidikan Berkemajuan dan Menggembirakan. Citing internet sources URL https://publikasiilmiah.ums.ac.id/bitstream/handle/11617/9571/63.pdf?se quence $=1$

[20] Pedoman Pimpinan Pusat Muhammadiyah. (2020) Citing internet sources https://dikdasmenppmuhammadiyah.org/wpcontent/uploads/2020/02/Pedoman-PP-Nomor-01-PED-I.0-B-2018Tentang-Pendidikan-Dasar-dan-Menengah-Muhammadiyah.pdf

[1] Badan Pusat Statistik Nasioanal Kota Padang. (2020). Citing internet sources URL https://www.dilut.com/jumlah-penduduk-kota-padang (diakses pada tanggal 01 Maret 2021)

[2] https://www.google.com/search?q=salinan+uu+no+20+tahun+2003\&oq=s

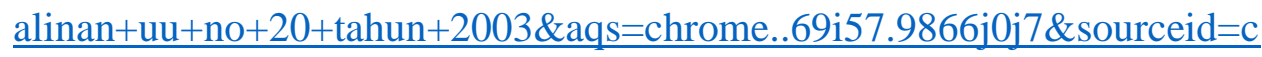
$\underline{\text { hrome } \& \text { ie }=U T F-8}$

[3] Depertemen Agama RI,. (1995). Al-Qur'an dan Terjemahnya, Semarang: Toha Putra Semarang.

[4] Hasbiyallah dan . Sulhan, Muhammad. (2013). Hadis Tarbawi dan HadisHadis di Sekolah dan Madrasah, Bandung.c Citing internet sources URL http://digilib.uinsgd.ac.id/10984/1/hadits\%20tarbawi.pdf

[5] Armalena. (2022). Wawancara dengan sejumlah siswa SD Muhammadiyah kecamatan Padang Timur 
[6] Visi dan Misi Disdakmen. (2021). Citing internet sources URL https://dikdasmenppmuhammadiyah.org/visi-misi/

[7] Joko Susilo. (2020). Seminar Nasional Kedua Pendidikan Berkemajuan dan Menggembirakan. Citing internet sources URL https:/publikasiilmiah.ums.ac.id/bitstream/handle/11617/9571/63.pdf?se quence $=1$

[8] Pedoman Pimpinan Pusat Muhammadiyah. (2020) Citing internet sources https://dikdasmenppmuhammadiyah.org/wpcontent/uploads/2020/02/Pedoman-PP-Nomor-01-PED-I.0-B-2018Tentang-Pendidikan-Dasar-dan-Menengah-Muhammadiyah.pdf 